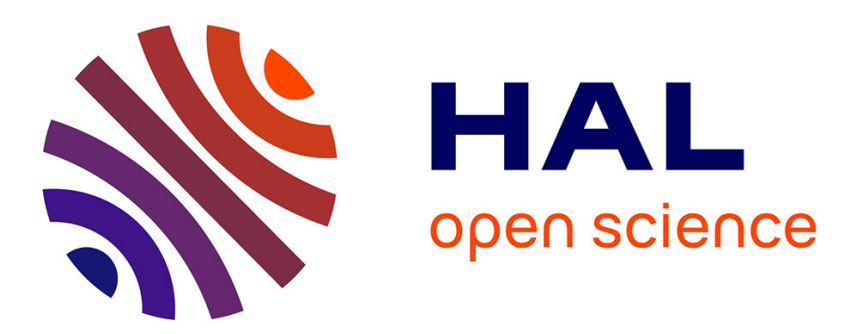

\title{
Terpyridine complexes of first row transition metals and electrochemical reduction of $\mathrm{CO}$ to $\mathrm{CO}$.
}

Noémie Elgrishi, Matthew B Chambers, Vincent Artero, Marc Fontecave

\section{To cite this version:}

Noémie Elgrishi, Matthew B Chambers, Vincent Artero, Marc Fontecave. Terpyridine complexes of first row transition metals and electrochemical reduction of CO to CO.. Physical Chemistry Chemical Physics, 2014, 16 (27), pp.13635-13644. 10.1039/c4cp00451e. hal-01069154

\section{HAL Id: hal-01069154 https://hal.science/hal-01069154}

Submitted on 31 May 2018

HAL is a multi-disciplinary open access archive for the deposit and dissemination of scientific research documents, whether they are published or not. The documents may come from teaching and research institutions in France or abroad, or from public or private research centers.
L'archive ouverte pluridisciplinaire HAL, est destinée au dépôt et à la diffusion de documents scientifiques de niveau recherche, publiés ou non, émanant des établissements d'enseignement et de recherche français ou étrangers, des laboratoires publics ou privés. 


\title{
Terpyridine complexes of first row transition metals and electrochemical reduction of $\mathrm{CO}_{2}$ to $\mathrm{CO}$
}

\author{
Noémie Elgrishi $^{a}$, Matthew B. Chambers ${ }^{a}$, Vincent Artero $^{b}$ and Marc Fontecave ${ }^{a, *}$ \\ Received (in $X X X, X X X) X$ th $X X X X X X X X X 20 X X$, Accepted Xth $X X X X X X X X X 20 X X$ \\ ${ }_{5}$ DOI: 10.1039/b000000x
}

Homoleptic terpyridine complexes of first row transition metals are evaluated as catalysts for the electrocatalytic reduction of $\mathrm{CO}_{2}$. $\mathrm{Ni}$ and Co-based catalytic systems are shown to reduce $\mathrm{CO}_{2}$ to $\mathrm{CO}$ under the conditions tested. The Ni complex was found to exhibit selectivity for $\mathrm{CO}_{2}$ over proton reduction while the Co-system generates mixtures of $\mathrm{CO}$ and $\mathrm{H}_{2}$ with $\mathrm{CO}: \mathrm{H}_{2}$ ratios being tuneable

10 through variations of the applied overpotential.

\section{Introduction}

The development of new energy storage technologies is central to solving the challenges facing the widespread use of renewable energies, namely their dilution and intermittent nature. ${ }^{1,2}$ Batteries 15 and hydrogen production are potential solutions which have been extensively investigated, but typically suffer from poor graviometric energy densities for the former and poor volumetric energy densities for the latter. ${ }^{3}$ A more attractive option is the reduction of carbon dioxide $\left(\mathrm{CO}_{2}\right)$ into carbon-based fuels, 20 combining higher graviometric and volumetric energy densities. This can be accomplished either directly through the generation of formic acid, methanol and higher hydrocarbons, or indirectly via the formation of carbon monoxide, which can be used as a feedstock chemical for the synthesis of alkanes through the ${ }_{25}$ Fischer-Tropsch process. Moreover, $\mathrm{CO}_{2}$ reduction presents the advantage of providing a global carbon neutral energy system, fitting into existing infrastructure and facilitating energy transport. ${ }^{4}$ This process can be achieved within an electrochemical cell in which electricity derived from renewable energy sources is 30 converted into chemical energy. ${ }^{5}$ However, the electroreduction of $\mathrm{CO}_{2}$ generally requires the presence of catalysts and the application of large overpotentials, since the reactions involve multiple electrons. Furthermore it suffers from limited selectivity since a mixture of the products mentioned above are generally obtained, 35 together with hydrogen $\left(\mathrm{H}_{2}\right)$, derived from the parallel reduction of protons required for activation of $\mathrm{CO}_{2}$. Molecular compounds have proven to be beneficial to the understanding of structure-activity relationships and the optimization of electrocatalytic systems. ${ }^{6,7,8}$ A challenging goal is the development of selective, efficient and 40 cheap catalysts. Cost limitation would require the combination of simple and robust ligands with first row transition metals.

Polypyridine ligands, such as bipyridine (bpy) and terpyridine

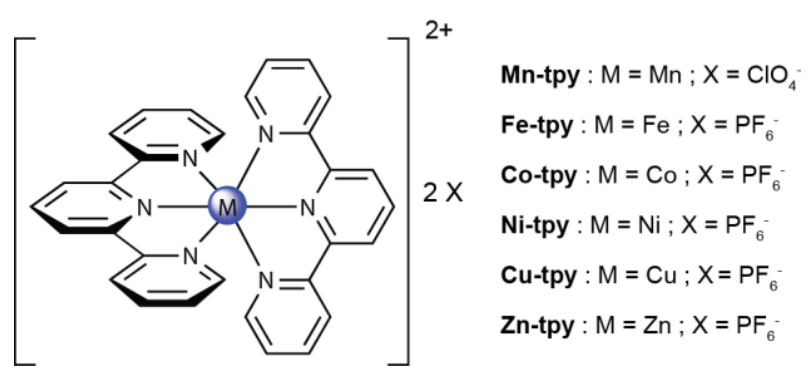

Scheme 1 Schematic depiction of the compounds studied.

45 (tpy), are common ligands in coordination chemistry and molecular catalysis as they generally generate stable well-defined complexes. ${ }^{9,10}$ As a consequence they have been frequently studied in the context of $\mathrm{CO}_{2}$ electroreduction in organic solvents, most often acetonitrile $\left(\mathrm{CH}_{3} \mathrm{CN}\right)$ or $\mathrm{N}, \mathrm{N}$-dimethylformamide (DMF), in 50 the presence of a source of protons. ${ }^{11}$ Such systems are capable of undergoing multiple reductions and thus storing multiple redox equivalents both in the ligand and in the metal ion. ${ }^{12,13}$ Surprisingly, little has been done using synthetic metalpolypyridine complexes with first row transition metals. Indeed, ${ }_{55}$ the best reported catalysts are based on $\mathrm{Re},{ }^{14,15,16} \mathrm{Rh}^{17,18,19}$ and $\mathrm{Ru},{ }^{20,21}$ using mostly bpy and only in a few cases tpy ligands. Recently, [Mn(bpy-R)(CO) 3 Br] (where bpy-R = substituted 2,2'bipyridines) complexes were reported as electrocatalysts for the reduction of $\mathrm{CO}_{2}$ to $\mathrm{CO}$ with reasonable efficiency, selectivity and 60 stability. ${ }^{22,23}$

Here we report on our investigation of $\left[\mathrm{M}(\mathrm{tpy})_{2}\right]^{2+}$ systems, with $\mathrm{M}=\mathrm{Co}, \mathrm{Ni}, \mathrm{Zn}, \mathrm{Mn}, \mathrm{Cu}, \mathrm{Fe}$ (noted M-tpy in the following, see Scheme 1) as, to our surprise, these complexes were incompletely characterized as electrocatalysts for $\mathrm{CO}_{2}$ reduction in solution. In 65 fact these systems were studied at the end of the 80's by Abruna and collaborators almost exclusively in a different context, namely that of electrodes modified with electropolymerized films of vinyltpy-M complexes. ${ }^{24,25,26,27,28}$ Here, on the basis of the first complete electrochemical characterization of M-tpy complexes, we show 70 that: (i) Co-tpy and Ni-tpy complexes display electrocatalytic 
properties for reduction of $\mathrm{CO}_{2}$ into $\mathrm{CO}$; (ii) within these complexes, polypyridine ligands such as tpy are highly susceptible to deleterious reactions which can explain the limited faradic yields.

\section{${ }_{5}$ Results}

\section{General experimental conditions}

All metal-terpyridine complexes were synthesized and characterized according to reported procedures. Schematic depictions of M-tpy are shown in Scheme 1. Standard protocols 10 for cyclic voltammetry and controlled-potential couloumetry experiments involved the use of DMF as a primary solvent in the presence of $0.1 \mathrm{M}$ TBAP (tetra- $n$-butylammonium perchlorate) and $5 \%$ water as a source of protons, under $\mathrm{CO}_{2}$-saturated conditions. The same bulk electrolyses experiments performed in ${ }_{15} \mathrm{CH}_{3} \mathrm{CN}$ as the primary solvent yielded comparable results, with the exception that some precipitate was observed. Following that which has been reported by Meyer and co-workers on analogous $\mathrm{Ru}$ polypyridyl systems, this precipitate is being tentatively assigned to be the result of reduced complex20 carbonate/bicarbonate salts. ${ }^{21}$ No evidence of precipitation was observed in DMF and thus, in order to limit side phenomena, DMF was used as the primary solvent for the studies reported herein. Since DMF can be subject to hydrolysis to yield formate or formaldehyde that is not derived from $\mathrm{CO}_{2}$ reduction, ${ }^{29}$ great 25 attention was paid to the product analysis in control experiments.

As shown in the supplementary information section, similar results were obtained when synthetic $\left[\mathrm{M}\left(\mathrm{ttpy}_{2}\right]^{2+}\right.$ complexes are replaced by a 1:2 mixture of the corresponding metal salt and the terpyridine ligand, respectively. All electrochemical potential 30 values are reported relative to that of the ferrocenium/ferrocene couple under the conditions used. The IUPAC convention is used to report current.

\section{Cyclic voltammetry}

To assess the reactivity of M-tpy $(\mathrm{M}=\mathrm{Mn}, \mathrm{Fe}, \mathrm{Co}, \mathrm{Ni}, \mathrm{Cu})$ 35 compounds towards $\mathrm{CO}_{2}$ at reducing potentials, cyclic voltammetry experiments were carried out in $\mathrm{DMF} / \mathrm{H}_{2} \mathrm{O}$ (95:5, v:v) solutions of each complex, in $\mathrm{Ar}$ and $\mathrm{CO}_{2}$-saturated conditions, with $0.1 \mathrm{M}$ of TBAP as the supporting electrolyte. Identical conditions were used for Zn-tpy except a 90:10 40 volumetric solvent ratio was used.

\section{Co-tpy}

The cyclic voltammogram under Ar of a $2 \mathrm{mM}$ solution of Co-tpy in a $\mathrm{DMF} / \mathrm{H}_{2} \mathrm{O}(95: 5, \mathrm{v}: \mathrm{v})$ mixture with $0.1 \mathrm{M}$ TBAP displays two 45 reversible one-electron electrochemical features in the -0.5 to -2.3 $\mathrm{V} v s . \mathrm{Fc}^{+} / \mathrm{Fc}$ range (Figure 1a, I and II). The first feature, at -1.17 $\mathrm{V} v s$. $\mathrm{Fc}^{+} / \mathrm{Fc}$, is a reversible metal-based process, assigned to a $\mathrm{Co}^{\mathrm{II}} / \mathrm{Co}^{\mathrm{I}}$ reduction (Figure 1a, II). This system is diffusion controlled, with a difference between the potential of the anodic 50 and cathodic peaks (peak-to-peak separation) of about $60 \mathrm{mV}$ at slow scan rates (59 to $64 \mathrm{mV}$ in the $10-100 \mathrm{mV} / \mathrm{sec}$ range). The peak-to-peak separation then increases as the scan rate is further increased to reach a separation of $77 \mathrm{mV}$ at a scan rate of 500 $\mathrm{mV} / \mathrm{sec}$. The plots of $\mathrm{i}_{\mathrm{pc}}$ and $\mathrm{i}_{\mathrm{pa}} v s . v^{1 / 2}$ are linear and the $\mathrm{i}_{\mathrm{pa}} / \mathrm{i}_{\mathrm{pc}}$ ratio
55 is close to unity in the $10-500 \mathrm{mV} / \mathrm{sec}$ scan rate range (Figure $\mathrm{S} 1$ ). This feature was used to determine the diffusion coefficient using the Randles-Sevick equation. A diffusion coefficient of $3.7 \cdot 10^{-6}$ $\mathrm{cm}^{2} / \mathrm{s}$ was calculated. The second electrochemical feature, at -2.03 $\mathrm{V} v s . \mathrm{Fc}^{+} / \mathrm{Fc}$, is attributed to a one-electron ligand-based reduction 60 (Figure 1a, I). This couple is mostly reversible, with a peak-to-peak separation of about $66 \mathrm{mV}$ for scan rates in the $10-50 \mathrm{mV} / \mathrm{sec}$ range. This value increases to $91 \mathrm{mV}$ at $1 \mathrm{~V} / \mathrm{s}$. Plots of $i_{p c}$ and $i_{p a}$ versus $v^{1 / 2}$ are linear over the range of scan rates studied, and the $\mathrm{i}_{\mathrm{pa}} / \mathrm{i}_{\mathrm{pc}}$ value is close to 1 which denotes chemical reversibility 65 (Figure S1).

As the potential range interrogated was increased to include more anodic potentials, $0 \mathrm{~V} v s$. $\mathrm{Fc}^{+} / \mathrm{Fc}$, a third feature at $-0.17 \mathrm{~V}$ vs. $\mathrm{Fc}^{+} / \mathrm{Fc}$ is observed and is attributed to the $\mathrm{Co}^{\mathrm{III}} / \mathrm{Co}^{\mathrm{II}}$ couple (Figure 1a, III). If the potential window scanned is increased to 70 more cathodic potentials values, an electrochemically irreversible wave is observed with a peak potential of $-2.46 \mathrm{~V} v s . \mathrm{Fc}^{+} / \mathrm{Fc}$ (Figure S2). This wave is accompanied by the apparition of two anodic features at -1.54 and $-0.76 \mathrm{~V} v s$. $\mathrm{Fc}^{+} / \mathrm{Fc}$ as well as a decrease in the intensity of the anodic waves of the $\mathrm{Co}^{\mathrm{II}} / \mathrm{Co}^{\mathrm{I}}$ and 75 tpy/tpy ${ }^{-}$couples. While investigating the lower potential ranges, as the number of scans is increased, the intensity of the anodic features of these two peaks continues to decrease. This additional irreversible feature at $-2.46 \mathrm{~V} v s . \mathrm{Fc}^{+} / \mathrm{Fc}$ is attributed to a second ligand-based reduction and appears to lead to decomposition 80 pathways. Therefore, the potential has always been controlled in the following work so as to avoid this deleterious reduction feature.

When the same solution was saturated with $\mathrm{CO}_{2}$, no difference was observed in the metal-based processes (Figure 1a, II and III). A strong enhancement of the cathodic current was observed in the 85 ligand-based reduction process, with an onset at $-1.80 \mathrm{~V} v s$. $\mathrm{Fc}^{+} / \mathrm{Fc}$ as can be seen in Figure 1a. The current increases over 4 folds, from -0.33 to $-1.51 \mathrm{~mA} / \mathrm{cm}^{2}$ (at $-2.23 \mathrm{~V}$, for a scan rate of 100 $\mathrm{mV} / \mathrm{s}$ ), and is stable over time. The wave becomes irreversible, with no anodic return-wave observed in the range of scan rates 90 studied $(10-1000 \mathrm{mV} / \mathrm{sec}$, Figure S1). It is thus assigned to catalytic $\mathrm{CO}_{2}$ reduction, which was confirmed by controlled potential electrolysis experiments.

\section{Ni-tpy}

${ }_{95}$ Cyclic voltammograms of a $2 \mathrm{mM}$ solution of Ni-tpy under inert atmosphere displays two reversible and diffusion-controlled electrochemical features at -1.62 and $-1.88 \mathrm{~V}$ vs. $\mathrm{Fc}^{+} / \mathrm{Fc}$ (Figure $1 \mathrm{~b}$, II and III). Both features are assigned to ligand-based electrochemical processes. Peak-to-peak separation of both 100 features are close to $60 \mathrm{mV}$ (62 and $65 \mathrm{mV}$ respectively at 100 $\mathrm{mV} / \mathrm{s}$ ) and the plots of $\mathrm{i}_{\mathrm{pc}}$ and $\mathrm{i}_{\mathrm{pa}} v s . v^{1 / 2}$ (Figure S3) are linear in the scan range studied $(10-1000 \mathrm{mV} / \mathrm{s})$, consistent with electrochemical and chemical reversibility.

At slow scan rates $(10-20 \mathrm{mV} / \mathrm{s})$, an additional small anodic 105 feature is observed at $-1.78 \mathrm{~V} \mathrm{vs}$. $\mathrm{Fc}^{+} / \mathrm{Fc}$ (Figure S4). This observation might be explained if slow chemical event is invoked, such as the loss of a tridentate tpy ligand, which is not observed at faster scan rates.

Under $\mathrm{CO}_{2}$-saturated conditions, the two electrochemical 110 features lose reversibility (no anodic return feature is observed) and the intensity of the corresponding cathodic peaks increase over 
2 fold, suggesting possible electrocatalytic behavior. A third

irreversible catalytic cathodic wave is observed at lower
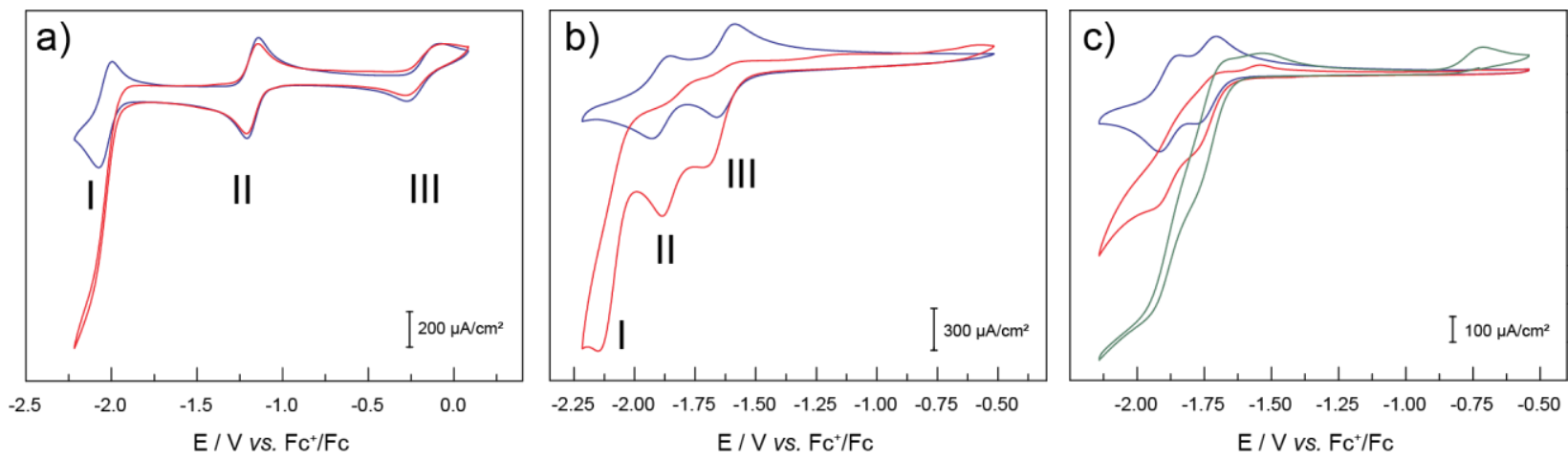

5 Fig. 1 Typical cyclic voltammograms of $2 \mathrm{mM}$ solutions of Co-tpy (a) and Ni-tpy (b) under argon (blue) and $\mathrm{CO}_{2}$ (red) atmospheres at $100 \mathrm{mV} / \mathrm{s}$. c): cyclic voltammograms at $100 \mathrm{mV} / \mathrm{s}$ of a $1 \mathrm{mM}$ solution of $\mathbf{Z n}$-tpy in DMF/ $\mathrm{H}_{2} \mathrm{O}(90: 10, \mathrm{v}: \mathrm{v})$ under argon (blue, only the third scan is presented), $\mathrm{CO}_{2}$ (red, only the third scan is presented), and under $\mathrm{CO}_{2}$ after the addition of over $20 \mathrm{mM}$ excess tpy ligand (green, only the third scan is presented).

potentials $\left(-2.15 \mathrm{~V}\right.$ vs. $\left.\mathrm{Fc}^{+} / \mathrm{Fc}\right)$, which is absent under $\mathrm{Ar}$ (Figure $1 \mathrm{~b}, \mathrm{I})$.

10

\section{Cu-tpy}

Evidence for deposition behaviour on glassy carbon electrode under $\mathrm{CO}_{2}$ was observed during cyclic voltammetry experiments of $2 \mathrm{mM} \mathrm{Cu}$-tpy solutions in DMF with $5 \% \mathrm{H}_{2} \mathrm{O}$ (Figure S5). This

15 heterogeneous behaviour is under further investigation and falls outside the scope of this paper.

\section{Fe-tpy and Mn-tpy}

Typical cyclic voltammograms of Fe-tpy and Mn-tpy are shown 20 in the supplementary information (Figure S6). Under the conditions used, no strong current enhancement upon addition of $\mathrm{CO}_{2}$ on the cyclic voltammetry responses was observed. This suggests a lack of electrocatalytic activity in the conditions tested, in contrast to previous reports as far as Fe-tpy is concerned, and 25 these complexes were not investigated further. ${ }^{26}$

\section{Zn-tpy}

The typical voltammogram of a $2 \mathrm{mM}$ solution of Zn-tpy exhibits two reversible electrochemical features, at -1.68 and $-1.81 \mathrm{~V} v s$. ${ }_{30} \mathrm{Fc}^{+} / \mathrm{Fc}$ (Figure 1c). Since the reduction of $\mathrm{Zn}^{\mathrm{II}}$ to $\mathrm{Zn}^{\mathrm{I}}$ is not likely to occur under these conditions, the two waves are assigned to ligand-based reduction processes. The two electrochemical features become irreversible and the intensity of the corresponding cathodic peaks significantly increase upon addition of $\mathrm{CO}_{2}$. It has 35 to be noted that a passivation of the glassy carbon electrode was observed as the number of scans was increased (Figure S7). As shown in Figure 1c, the intensity of the cathodic peaks is further increased upon addition of an excess of tpy ligand. When the same solution, containing excess tpy, is saturated with $\mathrm{Ar}$, the two waves

40 of Zn-tpy become reversible once more, with no visible contribution of additional equivalents of tpy to the current observed.

\section{Controlled-potential electrolyses}

In order to assess the catalytic activity of the various M-tpy 45 complexes under study and to characterize the catalyzed reaction, controlled-potential electrolysis of $\mathrm{CO}_{2}$-saturated $\mathrm{DMF} / \mathrm{H}_{2} \mathrm{O}$ (95:5, $\mathrm{v}: \mathrm{v})$ with $0.1 \mathrm{M}$ TBAP solution of each complex were carried out.
Quantitative analyses of $\mathrm{CO}$ and $\mathrm{H}_{2}$ formation were achieved by gas chromatography, formaldehyde ( $\mathrm{HCHO}$ ) formation by a 50 colorimetric assay and formic acid $(\mathrm{HCOOH})$ formation by ionexchange chromatography coupled to a conductimeter, as described in the experimental section. The presence of methane was assessed through gas chromatography, of methanol by ${ }^{1} \mathrm{H}$ and ${ }^{13} \mathrm{C}$ NMR and of oxalate by ionic exchange chromatography. ${ }_{55}$ Formaldehyde, methane, methanol and oxalate could not be detected in any of the following experiments.

\section{Co-tpy}

Electroreduction of $\mathrm{CO}_{2}$ in the presence of $2 \mathrm{mM}$ of Co-tpy results 60 in the exclusive formation of $\mathrm{CO}$ and $\mathrm{H}_{2}$ (in some cases tiny amounts of formate are also detected, always $<3 \%$ of the charge passed, but are attributed to deleterious reactions of DMF). Controlled-potential electrolysis at $-2.03 \mathrm{~V}$ yields sustained current over the course of 3 hours. During the first hour of the ${ }_{65}$ electrolysis, a decrease in the current is observed while the first $1.93 \mathrm{C}$ are exchanged before reaching the steady value of -0.39 $\mathrm{mA}$. This charge corresponds to about $2 \cdot 10^{-5}$ moles of electrons and is attributed to the first quantitative one-electron reduction of $\mathrm{Co}^{\mathrm{II}}$ to $\mathrm{Co}^{\mathrm{I}}$ prior to the formation of the catalytic species. Cyclic 70 voltammograms of the bulk solution after a $3 \mathrm{~h}$ electrolysis exhibit the same features as that of Co-tpy, but the open circuit potential was more negative than $-1.17 \mathrm{~V}$, indicating that most of the Cotpy species in solution was formally $\mathrm{Co}^{\mathrm{I}}$. The production of $\mathrm{CO}$ and $\mathrm{H}_{2}$ was constant over time in the region where the current 75 densities are stable, (Figure S8), corresponding to $17 \%$ faradic yield ( $12 \%$ for $\mathrm{CO}$ and $5 \%$ for $\mathrm{H}_{2}$ ).

In the absence of Co-tpy, a steady low background current of $19 \mu \mathrm{A}$ was observed, with background levels of CO $\left(1.6 \cdot 10^{-8}\right.$ moles $)$ and $\mathrm{H}_{2}\left(<6 \cdot 10^{-7}\right.$ moles) being formed after $3 \mathrm{~h}$. Electrolysis 80 of Co-tpy for $3 \mathrm{~h}$ in $\mathrm{N}_{2}$ saturated solution, in the absence of $\mathrm{CO}_{2}$, resulted in a continuous decrease of the current to levels observed without catalyst. At the end of the $3 \mathrm{~h}$ electrolysis, $3.31 \mathrm{C}$ were passed, corresponding to slightly under 2 equivalents of electrons per Co-tpy molecule. Background levels of $\mathrm{CO}$ and $\mathrm{H}_{2}$ were 85 detected during this experiment. In the absence of water, lower faradic yields, lower current and fewer moles of $\mathrm{CO}$ were observed (Figure S9). These experiments combined indicate that $\mathrm{CO}_{2}$ 

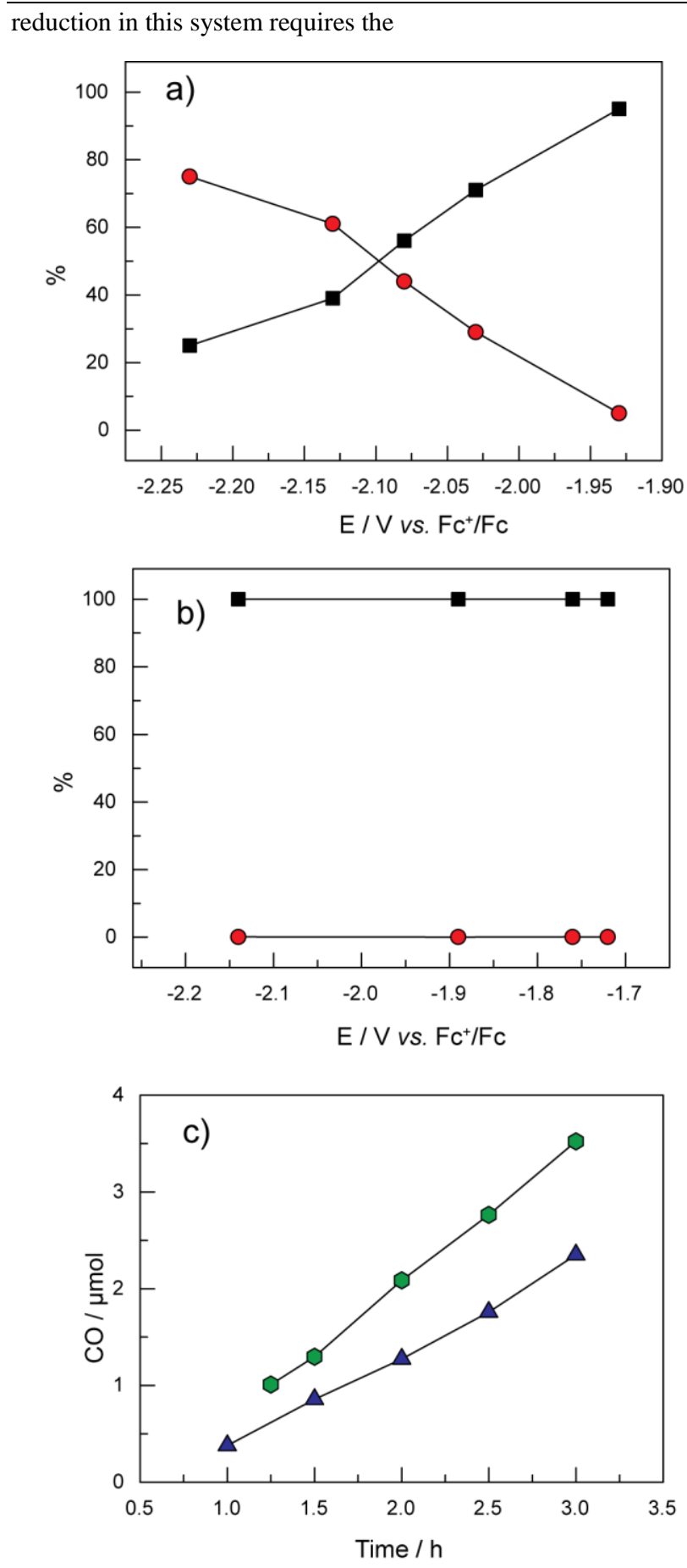

Fig. 2 Evolution of the proportions of $\mathrm{CO}$ (black squares) and $\mathrm{H}_{2}$ (red circles) among the products observed for $\mathrm{CO}_{2}$ reduction by Co-tpy (a)

5 and Ni-tpy (b) with the applied potential during controlled-potential electrolyses. c): comparison of the number of moles of $\mathrm{CO}$ produced by Ni-tpy (green hexagons) and Co-tpy (blue triangles) during the course of $3 \mathrm{~h}$ electrolyses at $-1.72 \mathrm{~V}$ for $\mathrm{Ni}$-tpy and -1.93V for Co-tpy. Carbon monoxide generation by the Ni-tpy system is better in these conditions

than for Co-tpy, even at a $\mathbf{2 0 0 ~ m V ~ l e s s ~ o v e r p o t e n t i a l ~ ( l i n e s ~ d r a w n ~ t o ~}$ guide the eye).

Co-tpy complex, $\mathrm{CO}_{2}$, and a proton source such as water.

The influence of the applied potential on product distribution was investigated by varying the applied potential in controlled15 potential electrolysis experiments. Five different potentials were tested, in the range of -1.93 to $-2.23 \mathrm{~V} \mathrm{vs}$. $\mathrm{Fc}^{+} / \mathrm{Fc}$. At all applied potentials tested, the current densities decrease during the first 30 minutes to $1 \mathrm{~h}$ (depending on the potential) corresponding in each case to about $1.93 \mathrm{C}$ before reaching a steady current density 20 (Figure S10). The stable current densities values increase upon decreasing the applied voltage (from $-0.29 \mathrm{~mA}$ at $-1.93 \mathrm{~V}$ to -1.28 $\mathrm{mA}$ at $-2.23 \mathrm{~V}$ ). The relative amounts of $\mathrm{H}_{2}$ and $\mathrm{CO}$ formed vary with the applied voltage, with the highest $\mathrm{CO}: \mathrm{H}_{2}$ ratio value of 20 obtained at $-1.93 \mathrm{~V}$ (Figure $2 \mathrm{a}$ ). The $\mathrm{CO}: \mathrm{H}_{2}$ ratio decreases to 0.3 25 as the applied potential was lowered to $-2.23 \mathrm{~V} \mathrm{vs.} \mathrm{Fc}^{+} / \mathrm{Fc}$, thus allowing a simple control of the produced $\mathrm{CO} / \mathrm{H}_{2}$ mixture by the potential applied during electrolysis. The combined faradic efficiency going towards $\mathrm{CO}$ and $\mathrm{H}_{2}$ was between $16-21 \%$, with little variation as the applied potential was varied.

30 Several routes were explored to account for the low faradic efficiency going towards $\mathrm{CO}_{2}$ reduction products. First the influence of solvent was investigated. To reduce reactivity of the methyl groups of DMF, $N, N$-diethylformamide (DEF) was tested as a solvent and 1-methyl-2-pyrrolidinone (NMP) was tested to 35 reduce the potential interference from reaction with the carbonyl group. These solvent variations lead to similar faradic yields for $\mathrm{CO}$ and $\mathrm{H}_{2}$ production (Figure $\mathrm{S} 11$ ). The influence of the electrolyte on the low faradic yields was also investigated. Sequential modifications of the cation from $\mathrm{TBA}^{+}$to $\mathrm{Li}^{+}$and of the 40 anion from $\mathrm{ClO}_{4}^{-}$to $\mathrm{PF}_{6}{ }^{-}$also lead to similar faradic efficiency (data not shown). Since Co-tpy is also known for $\mathrm{O}_{2}$ reduction catalysis, the influence of potential $\mathrm{O}_{2}$ leaks in the system during bulk electrolysis was investigated by performing the experiment in a $\mathrm{N}_{2}$ filled glovebag. No significant influence on faradic yields was 45 observed. Finally, as shown below, faradic yields increase upon decreasing tpy:Co ratios, during electrolysis of mixtures of tpy and $\mathrm{CoCl}_{2}$ and greatly decrease upon addition of an excess of bipyridine (table 1). All these results are consistent with the speculation that the low faradic efficiencies for $\mathrm{CO}_{2}$ reduction 50 results from the pyridine rings of the ligands being involved in side reactions under these conditions.

\section{Ni-tpy}

As shown by the cyclic voltammetry experiments, the onset 55 potential for electroreduction of $\mathrm{CO}_{2}$ catalyzed by the Ni-tpy system is less negative than in the Co-tpy system. Thus, electrolyses can be carried out at applied potentials as positive as $-1.72 \mathrm{~V}$, more than $200 \mathrm{mV}$ less negative than that required for electroreduction of $\mathrm{CO}_{2}$ catalyzed by Co-tpy. Two major features 60 differentiate the Ni-tpy system from the Co-tpy system: (i) larger but significantly less stable current densities at any applied potential from -1.72 to $-2.14 \mathrm{~V}$ and (ii) formation of $\mathrm{CO}$ as the unique reaction product, since no $\mathrm{H}_{2}$ could be detected (Figure $2 \mathrm{~b}$ ). However as in the case of Co-tpy, we could not account for the 65 total charge, since a Faradic yield of $20 \%$ at best was obtained with no effect of varying the applied potential (Figure S12). As with the Co-tpy system, ligand reactivity is proposed to explain at least in part the low yield. The two systems are compared in Figure 2c, in terms of $\mathrm{CO}$ production, which shows that under similar conditions ${ }_{70} \mathrm{CO}$ production is more efficient in the case of the Ni-tpy system. 


\section{Zn-tpy}

Controlled-potential electrolysis of a $5 \mathrm{mM}$ solution of Zn-tpy at $-2.15 \mathrm{~V}$ vs. $\mathrm{Fc}^{+} / \mathrm{Fc}$ in $\mathrm{CO}_{2}$-saturated conditions exhibits a current 5 of about $-1.8 \mathrm{~mA}$, which slowly decreases, as in the Ni-tpy case, to reach about $-0.8 \mathrm{~mA}$ after $3 \mathrm{~h}$ (Figure S13). Notably, no corresponding $\mathrm{CO}_{2}$ reduction products or $\mathrm{H}_{2}$ could be detected.

The paramagnetic nature of the cobalt and nickel based systems precluded investigations of degradation pathways through ${ }^{1} \mathrm{H}$ ${ }_{10} \mathrm{NMR}$, but the diamagnetic nature of $\mathrm{Zn}^{\mathrm{II}}$ allowed us to probe these side reactions. Assuming that $\mathrm{Zn}^{\mathrm{II}}$ catalyses the same side reactions responsible for the low faradic efficiency observed for Ni-tpy and Co-tpy under $\mathrm{CO}_{2}$-saturated conditions, the system was studied further.

15 Bulk electrolyses of $4 \mathrm{mM}$ solutions of terpyridine in the absence of $\mathrm{Zn}^{\mathrm{II}}$ at $-2.03 \mathrm{~V}$ or at $-2.23 \mathrm{~V} v s$. $\mathrm{Fc}^{+} / \mathrm{Fc}$ under $\mathrm{CO}_{2}$ lead to significant steady currents $(-0.13 \mathrm{~mA}$ at $-2.03 \mathrm{~V}$ and $-0.45 \mathrm{~mA}$ at $-2.23 \mathrm{~V})$, contrary to what is observed under inert atmosphere (Figure $\mathrm{S} 14)$. No $\mathrm{CO}_{2}$ reduction products or $\mathrm{H}_{2}$ can be detected in 20 these experiments as was the case for electrolysis of Zn-tpy solutions in the presence of $\mathrm{CO}_{2}$. This suggests the possibility that tpy transformation is a significant side reaction during catalysis that limits faradic efficiencies.

To experimentally probe the hypothesis of tpy being involved

25 in side reactions we investigated $\mathbf{Z n}$-tpy as a diamagnetic version of the system during both electroreduction and photoreduction of $\mathrm{CO}_{2}$, with the aim of using ${ }^{1} \mathrm{H}$ NMR spectroscopy to get some insight into the production of tpy-derived compounds. Photochemical reduction is considered as it provides the 30 opportunity to generate larger concentrations of such compounds more rapidly. Literature precedents suggest that in DMF, under $\mathrm{CO}_{2}$, at reducing potentials, $N$-heteroaromatic cycles can undergo $\mathrm{N}$-carboxylation reactions to yield compounds that can be trapped by addition of alkylating agents. ${ }^{30}$ In a first series of experiments a $355 \mathrm{mM}$ Zn-tpy solution was electrolysed at $-2.15 \mathrm{~V}$ during $4.5 \mathrm{~h}$. Iodomethane was then added to the solution which was stirred at room temperature for $1.5 \mathrm{~h} .{ }^{1} \mathrm{H}$ NMR of the resulting solution is consistent with a carboxylation reaction (see Figure S13 for experimental details). In a second series of experiments Zn-tpy 40 was photolysed in the presence of $\mathrm{CO}_{2}$ and $\left[\mathrm{Ru}(\mathrm{bpy})_{3}\right]^{2+}$ as the photosensitizer in MeCN/TEOA (triethanolamine, the sacrificial electron donor) and the resulting solution was analyzed by ${ }^{1} \mathrm{H}$ NMR (Figure S15). The ${ }^{1} \mathrm{H}$ NMR spectrum shows the presence of protons in the aliphatic region which are not originating from ${ }_{45}$ TEOA degradation pathways. This suggests a loss of aromaticity on the pyridine rings of the ligands and direct transformation of tpy. All these observations further support these pathways as contributing to the low faradic efficiencies of the reaction of $\mathbf{M}$ tpy with $\mathrm{CO}_{2}$.

50

\section{Mechanism probing and turnover frequencies}

Further analyses of the cyclic voltammetry data were performed in order to obtain some insight into the mechanistic pathway for $\mathrm{CO}_{2}$ reduction with the Co-tpy system. The reaction order in Co-tpy 55 was initially established via analysis of the catalytic peak current densities observed by cyclic voltammetry. The catalytic peak current varies linearly with the catalyst concentration (Figure S16), consistent with a mechanism for $\mathrm{CO}_{2}$ reduction that is first order in cobalt under these conditions on the CV time scale. An apparent 60 pseudo-first order rate constant of $10.4 \mathrm{~s}^{-1}$ was obtained using the foot-of-the-wave analysis proposed by Savéant and co-workers, ${ }^{31}$ applied to the cyclic voltammetry data
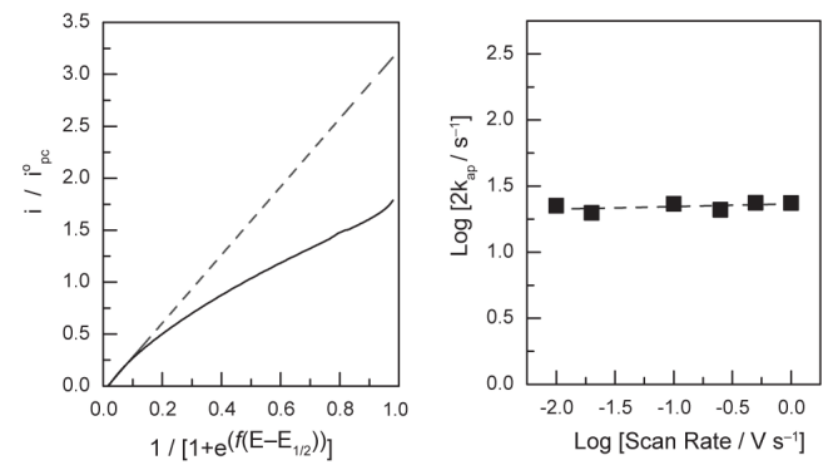

Fig. 3 Foot-of-the-wave analysis on the Co-tpy system at $250 \mathrm{mV} / \mathrm{s}$ (left), 65 $f=F /(R T)$, and plot of $\log \left(2 \mathrm{k}_{\mathrm{ap}}\right)$ as a function of scan rate (right).

collected exclusively with a Co-tpy concentration equal to 2.0 $\mathrm{mM}$. The details of the analysis can be found in the SI. As expected when the assumptions of the foot-of-the-wave analysis are met, this rate constant is virtually invariant with respect to two orders of 70 magnitude of scan rate analysed (Figure 3, right).

Under the experimental conditions used, one can estimate a turnover frequency of about $3.2 \cdot 10^{-10} \mathrm{~s}^{-1}$ at zero overpotential for the production of $\mathrm{CO}$, which is within an order of magnitude to that which has been reported for other polypyridyl based $\mathrm{CO}_{2}$ reduction 75 catalysts of various transition metals. ${ }^{32}$ In this calculation, the $\mathrm{CO} / \mathrm{CO}_{2}$ reduction potential in a $\mathrm{DMF} /$ water solvent mixture is estimated to be $-1.41 \mathrm{~V}$ vs. $\mathrm{Fc}^{+} / \mathrm{Fc}$, as the $\mathrm{CO} / \mathrm{CO}_{2}$ potential is reported to be $-0.690 \mathrm{~V}$ vs. $\mathrm{NHE}^{32}$ and the $\mathrm{Fc}^{+} / \mathrm{Fc}$ potential is reported to be $0.720 \mathrm{~V}$ vs. NHE in DMF. ${ }^{33}$ The catalytic cyclic 80 voltammograms of Co-tpy display substantial current enhancement with an applied potential of $-2.08 \mathrm{~V} \mathrm{vs}$. $\mathrm{Fc}^{+} / \mathrm{Fc}$, which represents an applied overpotential of $0.67 \mathrm{~V}$. This overpotential can be factored into the TOF calculation and a TOF within the catalytic wave was determined to be $74 \mathrm{~s}^{-1}$.

85 Deviations of the experimental data from the idealized s-shaped catalytic activity curve within the foot-of-the-wave analysis begin very soon after the onset of catalytic activity (Figure 3, left). Qualitatively, the strong deviations observed are in agreement with either fast substrate consumption or product inhibition of catalysis. 90 Despite our inability to conclusively differentiate between the types of deviations, the relatively low intrinsic catalytic activity of Co-tpy suggests that fast substrate consumption (faster than rates of substrate diffusion) is not likely the cause of the deviation being observed, thus making fast product inhibition the likely cause of 95 the deviation for idealized behaviour.

Controlled-potential electrolyses experiments were also used to gain an insight into the mechanism. Bulk electrolysis at a fixed applied potential of $-2.03 \mathrm{~V}$ were carried out on solutions of Cotpy at different concentrations in order to assess the order of Co100 tpy under steady state conditions as opposed to fast time scales previously probed by $\mathrm{CV}$ experiments. The faradic yields for $\mathrm{CO}$ and $\mathrm{H}_{2}$ production were constant in the range of concentration tested. The potential was also varied in a step-wise manner. The results, as shown in Figure S17, indicate that under steady-state 105 bulk electrolysis conditions the apparent order in cobalt was 0.5 at 
the 5 potentials tested between in the -1.97 to $-2.07 \mathrm{~V}$ potential range. The order then increased to 0.74 as the potential was further decreased to more negative values, probably because of less stable current densities. Of importance is that the order in Co-tpy was 5 found to be 1 under the fast time scale conditions of a $\mathrm{CV}$ experiment (Figure S16) but was found to definitely be less than 1 (likely 0.5 ) under steady state conditions. This difference is attributed to an inhibition process that occurs under steady state conditions and will be elaborated upon within the Discussion 10 Section.

A plot of potential $v s$. the log of the total current, a Tafel plot, at various catalyst concentrations was extracted from the experimental bulk electrolysis data. The data are shown in Figure S18. At all concentrations, linearity was observed over a short 15 range of potentials from -1.9 to $-2.1 \mathrm{~V}$ with a slope of $135 \mathrm{mV} / \mathrm{dec}$. This slope of approximately $120 \mathrm{mV} / \mathrm{dec}$ is indicative of rate limiting electron transfer from the electrode. As the potential is stepped to more negative values, the slope increases rapidly to reach values $>1 \mathrm{~V} / \mathrm{dec}$. This supports either a chemical rate 20 determining step or mass transport limitation to the apparent kinetics. The lack of a pre-equilibrium electron transfer step inhibits our ability to utilize electrochemistry to probe further into mechanistic aspects of electrocatalytic reduction of $\mathrm{CO}_{2}$ by $\mathrm{Co}-$ tpy.

25 Since there are no available coordination sites for interaction with $\mathrm{CO}_{2}$ in $\left[\mathrm{Co}(\text { tpy })_{2}\right]^{+}$, it was assumed that a catalytic species different from the starting complex was generated during bulk electrolysis resulting from either decoordination of a pyridine ring of tpy or complete loss of a tpy ligand. In order to assess the ligand30 to-metal stoichiometry of the catalytically relevant species, a methodology used by Sauvage and $\mathrm{Lehn}^{34}$ in the study of $\mathrm{CO}_{2}$ photo-reduction by the analogous $\left[\mathrm{M}(\mathrm{bpy})_{\mathrm{n}}\right]^{\mathrm{m}+}$ complexes was followed, in which the efficiency of the catalysis, during bulk electrolyses, was assessed while the tpy:Co ratio was varied by 35 combining tpy with $\mathrm{CoCl}_{2}$ salt. The results, in terms of the faradic efficiency for $\mathrm{CO}$ production, are summarized in table 1 (additional data provided in Figure S19).

Table 1: influence of the relative concentrations (mM) of tpy, $\mathrm{CoCl}_{2}$ and bpy and of time on $\mathrm{CO}$ faradic yields $\left(\%_{\mathrm{co}}\right)$ observed during bulk 40 electrolyses at $-2.03 \mathrm{~V} \mathrm{vs.} \mathrm{Fc}^{+} / \mathrm{Fc}$.

\begin{tabular}{ccccc}
\hline tpy & bpy & $\mathrm{CoCl}_{2}$ & $\%_{\mathrm{CO}} 1 \mathrm{~h}-2 \mathrm{~h}$ & $\%_{\mathrm{CO}} 2 \mathrm{~h}-3 \mathrm{~h}$ \\
\hline 4 & 0 & 2 & 7 & 6 \\
2 & 0 & 2 & $38^{\mathrm{a}}\left(76^{\mathrm{b}}\right)$ & 11 \\
2 & 2 & 2 & 8 & 3 \\
2 & 0 & 0 & 0 & 0 \\
1 & 0 & 2 & 46 & 16 \\
0 & 0 & 2 & 1 & 4
\end{tabular}

a: Measured between minutes 45 and 90 of electrolysis. ${ }^{\text {b. }}$ Measured between minutes 45 and 60 of electrolysis.

At $-2.03 \mathrm{~V} v s . \mathrm{Fc}^{+} / \mathrm{Fc}$, solutions of $2 \mathrm{mM} \mathrm{CoCl}_{2}$ appear to exhibit electrocatalytic activity. This system is highly unstable, as the 45 current intensity continuously decreased down to baseline levels during the $3 \mathrm{~h}$ electrolysis, and produced almost exclusively $\mathrm{H}_{2}$ with only traces of $\mathrm{CO}$ (data not shown). This is attributed to the formation of $\mathrm{Co}^{0}$ nanoparticles which can be rendered electrochemically inert via amalgamation with the mercury, thus 50 explaining the constant drop in current densities. When solutions of terpyridine are electrolyzed at $-2.03 \mathrm{~V}$ under $\mathrm{CO}_{2}$, a steady current is observed but no $\mathrm{CO}$ or $\mathrm{H}_{2}$ could be detected. As the tpy:Co ratio is decreased, faradic efficiencies for $\mathrm{CO}$ production are increased, with the highest recorded value of $76 \%$ during the 55 beginning of the electrolysis of a 1:1 Co/tpy mixture. These results tend to suggest a catalytic species composed of at most 1 equivalent of terpyridine per cobalt centre.

\section{Discussion}

Polypyridyl-supported metal compounds have been extensively 60 utilized in the electrocatalytic reduction of $\mathrm{CO}_{2}$, with $\left[\mathrm{Re}\left({ }^{\mathrm{t}} \mathrm{Bu}-\right.\right.$ bpy)(CO) $\left.{ }_{3} \mathrm{Cl}\right]$ and $[\mathrm{Ru}$ (tpy)(bpy)(solvent)] being the most efficient and well-studied catalysts, among others. ${ }^{16,22,35,36}$ All of these compounds have been shown to catalyze the reduction of $\mathrm{CO}_{2}$ to carbon monoxide or formate, and in most cases $\mathrm{H}_{2}$ was observed 65 as well. Despite the success of such polypyridyl-supported noble metal catalysts, fewer examples of first row transition metal polypyridyl-based $\mathrm{CO}_{2}$ reduction electro-catalysts are present in the literature, with the most active ones being based on variations of the $\left[\mathrm{Mn}(\mathrm{bpy})(\mathrm{CO})_{3} \mathrm{Br}\right]$ catalyst developed by Deronzier and 70 collaborators. ${ }^{22,23}$

In all of these cases, the polypyridine backbone was advantageous due to its redox active nature and thus should be considered as a non-innocent ligand. ${ }^{18,21,37}$ Multiple equivalents of electrons are thus able to be stored on such catalysts, which 75 facilitates multi-electron reactivity with $\mathrm{CO}_{2}$, avoiding the highly energetic one-electron reduction of $\mathrm{CO}_{2}$ to $\mathrm{CO}_{2}{ }^{--} .38$ The reduced polypyridyl rings act as the reservoir of electrons for $\mathrm{CO}_{2}$ reduction, and the metal centre mediates the transfer of these reducing equivalents to $\mathrm{CO}_{2}$.

${ }_{80}$ We sought to gain general insight into the electrocatalytic behaviour of meridionally coordinated terpyridine $3 \mathrm{~d}$ transition metal complexes by revisiting work initiated by H. D. Abruna, albeit in a different context. ${ }^{25,26,27,28}$ Although the initial reports indicate a possible activity of the Cr-tpy derivatives, ${ }^{28}$ we focused 85 our attention on late transition metals, seeking to understand underlying differences in the reactivity of the $\mathrm{Co}$ and $\mathrm{Ni}$ derivatives specifically, as well as gleaning insight into the general reaction mechanism.

The central role of ligand reduction in mechanisms postulated 90 for polypyridyl-based $\mathrm{CO}_{2}$ reduction catalysts highlights the importance of understanding the reduction potential assignments within the cyclic voltammetry experiments. The assignments of the waves in the cyclic voltammograms of the M-tpy complexes are the subject of multiple differing interpretations. Originally, in the 95 case of Ni-tpy the two reduction waves (Figure 1b, III and II) were assigned as metal-based and ligand-based, respectively. ${ }^{26,27} \mathrm{We}$ have found, by comparison with Zn-tpy, that the waves would be better described as both being ligand-based. This is further supported by recent studies on the electronic structure of $\mathrm{Ni}$ 100 monoterpyridine and $\left[\mathrm{Ni}(\mathrm{tpy})_{2}\right]^{2+}$ compounds. ${ }^{39,40}$ In contrast, in the case of Co-tpy, reduction of the ligand occurs at potentials more negative than those required to generate the $\mathrm{Co}^{\mathrm{I}}$ species.

These assignments have implications on the electronic structure of the catalytic species and point to a possible significant 105 difference between the $\mathrm{Co}$ and Ni-based catalysts: during 
controlled-potential electrolysis, the bulk solution mostly contains $\mathrm{Co}^{\mathrm{I}}$ in the Co-tpy case, but $\mathrm{Ni}^{\mathrm{II}}$ in the $\mathbf{N i}$-tpy case. This has a strong impact on the possible mechanistic pathways. $\mathrm{Co}^{\mathrm{I}}$ centres have been shown to lead, upon reaction with protons, to the formation 5 of a $\mathrm{Co}^{\mathrm{III}}-\mathrm{H}$ which would then be implicated in $\mathrm{H}_{2}$ evolution, ${ }^{41,42,43,44,45,46}$ which has been demonstrated in related

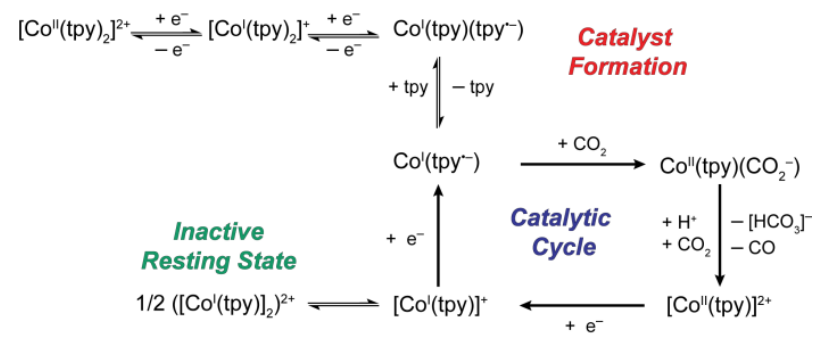

Scheme 2 Proposed mechanism for $\mathrm{CO}_{2}$ reduction to $\mathrm{CO}$ by Co-tpy.

polypyridyl-based cobalt complexes as well..$^{47,48,49}$ This is in sharp 10 contrast with the $\mathrm{Ni}$-based system, since a Ni ${ }^{\mathrm{IV}}-\mathrm{H}$ resulting from the protonation of a $\mathrm{Ni}^{\mathrm{II}}$ centre is unlikely to form in the conditions of the experiment. ${ }^{50,51,52,53}$ This would explain the distinct difference in reactivity of the two catalytic systems in terms of product distribution, since metal hydrides are required for $\mathrm{H}_{2}$ 15 evolution but are not necessarily needed for $\mathrm{CO}_{2}$ reduction, and are often not invoked in the specific case of $\mathrm{CO}_{2}$ reduction to $\mathrm{CO}$. Thus, as confirmed herein, Co-tpy is more susceptible than Ni-tpy to proton reduction, in parallel to conversion of $\mathrm{CO}_{2}$ into $\mathrm{CO}$. However, we showed that the selectivity of the reaction in the case 20 of Co-tpy can be easily tuned upon varying the applied voltage (Figure 2a). Indeed, at the lowest potentials electrolysis generated $\mathrm{CO}$ almost exclusively, while decreasing the potential resulted in a drop of the $\mathrm{CO}: \mathrm{H}_{2}$ ratio, with a $\mathrm{CO}: \mathrm{H}_{2}$ value of 1 at about -2.1 V.

25 To allow for direct interaction between $\mathrm{CO}_{2}$ and the metal centre, the ability of the system to liberate a coordination site is crucial. This is achieved in Ru-based catalysts ${ }^{35}$ by the exchange of a solvent molecule for $\mathrm{CO}_{2}$, in $\left[\mathrm{M}(\mathrm{bpy})_{3}\right]$ compounds by the prior loss of a bpy ligand ${ }^{54}$ and in the case of $\left[\mathrm{Re}(\mathrm{bpy})(\mathrm{CO})_{3} \mathrm{Cl}\right]$ the 30 opening of a coordination site through loss of the $\mathrm{Cl}$ ligand is triggered by bpy reduction. ${ }^{55}$ Similarly, we propose that ligand reduction triggers the loss of the second (neutral) terpyridine ligand, as supported by the Ni-tpy CVs at slow scan rates and as has been proposed for analogous cobalt-based systems. ${ }^{56}$

35 The proposed mechanism for Co-tpy is depicted in Scheme 2, where solvent, electrolytes, or other Lewis bases complete the coordination sphere around the cobalt. We propose that the $\left[\mathrm{Co}^{\mathrm{II}}(\mathrm{tpy})_{2}\right]^{2+}$ compounds acts as the pre-catalyst. Upon reduction of first $\mathrm{Co}^{\mathrm{II}}$ to $\mathrm{Co}^{\mathrm{I}}$ and then tpy to tpy ${ }^{\bullet-}$, a neutral terpyridine ligand 40 is lost, generating a catalytically active species with a stoichiometry of 1 tpy per Co. In steady state bulk electrolysis conditions however, we propose that a resting state dimeric species forms where two $\left[\mathrm{Co}^{\mathrm{I}}(\mathrm{tpy})\right]$ centres are bridged, possibly by carbonates or carbonyl groups, as has been reported in analogous 45 structures in the literature. ${ }^{57,58,59,60,61,62}$ The carbonates could possibly originate either from a $\mathrm{CO}_{2}$ /water equilibrium or as an outcome of $\mathrm{CO}$ formation. The necessity for this dimer to break apart, liberating the Co monoterpyridine catalyst, is supported by the apparent order of 0.5 observed in these conditions, as well as 50 the observation from the Tafel data that of a chemical limiting step.
The foot-of-the-wave analysis further supports the claim of product inhibition. By analogy with reported mechanism for $\mathrm{CO}$ formation on related polypyridine compounds, we propose the substitution of $\mathrm{CO}_{2}$ for a solvent molecule in the $\left[\mathrm{Co}^{\mathrm{I}}\left(\operatorname{tpy}^{\bullet-}\right)\right]$ entity, which then ${ }_{55}$ reacts with a second $\mathrm{CO}_{2}$ molecule and $\mathrm{H}^{+}$to yield a $\mathrm{Co}-\mathrm{CO}$ intermediate, which eventually releases $\mathrm{CO}$ and $\mathrm{HCO}_{3}{ }^{-}$. This mechanism for $\mathrm{CO}$ generation likely can be extended to Ni-tpy, however the two catalytically relevant reduction events for the catalyst would be primarily ligand based.

60 An alternate pathway, paralleling $\mathrm{CO}$ and $\mathrm{H}_{2}$ formation, explains the low Faradic yield. It is likely that the reduction of the tpy ligand renders it highly susceptible to further reactions, such as carboxylations,Erreur! Signet non défini. or possibly hydrogenation $^{18}$, which compete with $\mathrm{CO}$ and $\mathrm{H}_{2}$ formation.

${ }_{65}$ Previous reports in the case of noble metal-based systems have also pointed to such a parallel process that might explain the low faradic yields. ${ }^{17,18}$ However it seems that the late first row transition metals are less efficient in avoiding these reactions as faradic yields for $\mathrm{CO}+\mathrm{H}_{2}$ are significantly lower in that case.

\section{${ }_{70}$ Experimental section}

\section{General considerations}

M-tpy compounds were synthesized according to modified literature procedures. ${ }^{26,63,64}$ Hexadistilled mercury used for bulk electrolyses was purchased from Ophram. Annealed platinum wire 75 was purchased from Alfa Aesar. Anhydrous solvents ( $N, N$ dimethylformamide, $\quad N, N$-diethylformamide, 1-methyl-2pyrrolidinone and acetonitrile), tetra- $n$-butylammonium perchlorate, lithium perchlorate, tetra- $n$-butylammonium hexafluorophosphate, cobalt(II) chloride, zinc chloride, nickel(II) 80 chloride, manganese(II) perchlorate hydrate, iron(II) chloride, copper(II) chloride, iodomethane, tris(2,2'bipyridyl)dichlororuthenium(II) hexahydrate, triethanolamine, 2,2':6', $2^{\prime \prime}$-terpyridine, 2,2'-bipyridyl, acetonitrile- $\mathrm{d}_{3}$ and deuterium oxide were purchased from Sigma-Aldrich and used as received. ${ }_{85}^{1} \mathrm{H}$ NMR was performed on a Brücker $300 \mathrm{MHz}$ instrument.

\section{Cyclic voltammetry experiments}

All cyclic voltammetry experiments were carried out in a singlecompartment cell using a $1 \mathrm{~mm}$ diameter glassy carbon electrode (from Bio-Logic) unless otherwise noted. The electrode was 90 polished before each measurement with a $1 \mu \mathrm{m}$ diamond suspension. A Pt wire counter electrode was used, with a $\mathrm{Ag} / \mathrm{AgCl}$, $3 \mathrm{M} \mathrm{KCl}$ reference electrode separated from the solution by a Vycor tip. IR drop was compensated to $85 \%$ using the ZIR built-in compensation method of the SP 300 Bio-Logic potentiostat used.

95 All electrochemical data were referenced to the potential of the $\mathrm{Fc}^{+} / \mathrm{Fc}$ couple in the solvent system used. The IUPAC convention was used to report current. The supporting electrolyte used was tetrabutylammonium perchlorate (TBAP) at a concentration of 0.1 $\mathrm{M}$ in $\mathrm{DMF} / \mathrm{H}_{2} \mathrm{O}$ mixtures. All solutions were purged with inert gas $100\left(\mathrm{~N}_{2}\right.$ or $\left.\mathrm{Ar}\right)$ or $\mathrm{CO}_{2}$ for at least 15 minutes before $\mathrm{CVs}$ were recorded. Unless otherwise noted, at least 10 superimposable scans were recorded for each experiment to insure the equilibrium was reached.

\section{Controlled-potential electrolyses}

105 Bulk electrolysis experiments were carried out in a custom made 
two-compartment cell (Figure S20). A $1.5 \mathrm{~cm}$ diameter pool of mercury was used as working electrode unless otherwise noted. The counter electrode used was a platinum wire separated from the working electrode by a porous 4 frit, and an $\mathrm{Ag} / \mathrm{AgCl}, 3 \mathrm{M} \mathrm{KCl}$ 5 reference electrode was separated from the solution by a Vycor tip. The volume of solution used in the working compartment of the cell is $10 \mathrm{~mL}$, and the typical headspace volume is $31 \mathrm{~mL}$. No IR compensation was done for bulk electrolyses. A Bio-Logic SP 300 potentiostat connected to a booster card was used to apply potential 10 and record charge and current. Bulk electrolysis solutions were purged with inert gas or $\mathrm{CO}_{2}$ for 15 min prior to electrolysis. Solutions were constantly stirred throughout bulk electrolysis experiments.

\section{Chemical analysis}

$15 \mathrm{H}_{2}$ measurements were performed by gas chromatography on a Shimadzu GC-2014 equipped with a Quadrex column, a Thermal Conductivity Detector and using $\mathrm{N}_{2}$ as a carrier gas. $\mathrm{CO}$ was measured using a Shimadzu GC-2010 Plus gas chromatography, fitted with a Restek Shin Carbon column, helium carrier gas, a 20 methanizer and a Flame Ionization Detector. Gas chromatography calibration curves were made by sampling known volumes of $\mathrm{CO}$ and $\mathrm{H}_{2}$ gas respectively. The typical volume of gas injected was 50 $\mu \mathrm{L}$. The presence of $\mathrm{CH}_{4}$ was assessed using the same set-up.

Formate and oxalate concentrations were determined using a 25 Metrohm 883 Basic IC plus ionic exchange chromatography instrument, using a Metrosep A Supp 5 column and a conductivity detector. A typical measurement requires the sampling of $1 \mathrm{~mL}$ of solution, followed by a 100 fold dilution in deionised $18 \mathrm{M} \Omega / \mathrm{cm}$ water and injection of $20 \mu \mathrm{L}$ into the instrument. Caution is 30 necessary when determining formate concentrations if DMF is being employed as a solvent. Great care must be taken to separate the counter electrode from the working electrode as formate is generated at the counter electrode through one-electron oxidation of DMF followed by hydrolysis.

35 Formaldehyde concentration was determined using the Nash colorimetric test ${ }^{65}$ using a Shimadzu UV-1800 instrument. We observed that post-electrolysese solutions containing DMF and Co-tpy must be analysed for formaldehyde quickly as reoxidation in air led to increasing amounts of formaldehyde being produced, 40 which is attributed to the reaction of DMF with a Co ${ }^{\mathrm{III}}$-tpy, generated through the reaction of $\mathbf{C o}^{\mathrm{II}}$-tpy with $\mathrm{O}_{2}$.

Methanol presence was assessed using a Shimadzu GC-2010 Plus gas chromatography fitted with a ZB-WAX Plus column, Helium as a carrier gas and a flame ionization detector. $\mathrm{MeOH}$ ${ }^{45}$ presence was also assessed through ${ }^{1} \mathrm{H}$ NMR spectroscopy on a Brücker $300 \mathrm{MHz}$ Instrument.

\section{Conclusions}

We have shown that homoleptic terpyridine complexes of nickel and cobalt are competent catalysts for the electrocatalytic 50 reduction of $\mathrm{CO}_{2}$ to $\mathrm{CO}$ as the exclusive carbon containing product. The catalysis is observed to begin by reduction of a tpy ligand for both the Ni-tpy and Co-tpy systems. The systems differ in that the resting state of the Co-tpy catalyst is assigned to be monovalent cobalt whereas the resting state of the Ni-tpy catalyst is assigned 55 to be divalent nickel. The higher valent nickel catalyst is proposed to be unable to generate intermediate nickel-hydrides required for hydrogen generation in the conditions used and thus exhibits remarkable selectivity for $\mathrm{CO}_{2}$ reduction to $\mathrm{CO}$ over proton reduction. The lower valent cobalt catalyst is found to generate 60 gaseous mixtures of $\mathrm{CO}$ and $\mathrm{H}_{2}$, the ratio of which can be tuned base on the overpotential which is applied. Decomposition of the polypyridyl ligand has been shown to be the primary pathway which limits overall faradic efficiency, even though the intrinsic catalytic activity for the cobalt based system is comparable to that 65 which has been reported for other metal-polypyridyl catalysts.

\section{Acknowledgements}

We acknowledge support from Fondation de l'Orangerie for individual Philanthropy and its donors and from the French National Research Agency (ANR, Carbiored ANR-12-BS0770 0024-03). This work was supported by the French State Program 'Investissements d'Avenir' (Grants "LABEX DYNAMO”, ANR11-LABX-0011-01 and LABEX ARCANE, ANR-11-LABX0003-01). The authors would like to thank Dr. P. Simon for efforts towards the development of initial detection methods for formate 75 through a colorimetric coupling method and of formaldehyde through a chromotropic acid test and J. P. Porcher for initial help with setting-up $\mathrm{H}_{2}$ measurements. N. E. acknowledges the Direction Générale de l'Armement (DGA) for a graduate research fellowship.

\section{${ }_{80}$ Notes and references}

${ }^{a}$ Laboratoire de Chimie des Processus Biologiques, UMR 8229 CNRS, Université Pierre et Marie Curie - Paris 6, Collège de France, 11 Place Marcelin Berthelot, 75231 Paris Cedx 05, France. Fax: +331 44271356; Tel: +33 1 44271360; E-mail : marc.fontecave@cea.fr

${ }_{85}{ }^{b}$ Laboratoire de Chimie et Biologie des Métaux, Université Grenoble Alpes, CNRS UMR 5249, CEA, 17 avenue des martyrs, 38054 Grenoble Cedex 9, France. Tel: +33438789122

$\uparrow$ Electronic Supplementary Information (ESI) available: additionnal information as noted in the text. See DOI: 10.1039/b000000x/

1 N. S. Lewis and D. G. Nocera, Proc. Natl. Acad. Sci., 2006, 103, 15729.

2 T. Faunce, S. Styring, M. R. Wasielewski, G. W. Brudvig, A. W. Rutherford, J. Messinger, A. F. Lee, C. L. Hill, H. deGroot, M. Fontecave, D. R. MacFarlane, B. Hankamer, D. G. Nocera, D. M. Tiede, H. Dau, W. Hillier, L. Wang and R. Amal, Energy Environ. Sci., 2013, 6, 1074. 
3 T. R. Cook, D. K. Dogutan, S. Y. Reece, Y. Surendranath, T. S. Teets and D. G. Nocera, Chem. Rev., 2010, 110, 6474.

4 H. Arakawa, M. Aresta, J. N. Armor, M. A. Barteau, E. J. Beckman, A. T. Bell, J. E. Bercaw, C. Creutz, E. Dinjus, D. A. Dixon, K. Domen, D. L. DuBois, J. Eckert, E. Fujita, D. H. Gibson, W. A. Goddard, D. W. Goodman, J. Keller, G. J. Kubas, H. H. Kung, J. E. Lyons, L. E. Manzer, T. J. Marks, K. Morokuma, K. M. Nicholas, R. Periana, L. Que, J. Rostrup-Nielson, W. M. H. Sachtler, L. D. Schmidt, A. Sen, G. A. Somorjai, P. C. Stair, B. R. Stults and W. Tumas, Chem. Rev., 2001, 101, 953.

5 J. L. Inglis, B. J. MacLean, M. T. Pryce and J. G. Vos, Coord. Chem. Rev., 2012, 256, 2571.

6 M. Rakowski DuBois and D. L. DuBois, Acc. Chem. Res., 2009, 42, 1974.

7 E. E. Benson, C. P. Kubiak, A. J. Sathrum and J. M. Smieja, Chem. Soc. Rev., 2009, 38, 89.

8 A. J. Morris, G. J. Meyer and E. Fujita, Acc. Chem. Res., 2009, 42, 1983.

9 A. Winter, G. R. Newkome, U. S. Schubert, Chem. Cat. Chem., 2011, 3, 1384.

10 C. Kaes, A. Katz and M. W. Hosseini, Chem. Rev., 2000, 100, 3553.

11 J.-M. Savéant, Chem. Rev., 2008, 108, 2348.

12 C. C. Scarborough, K. M. Lancaster, S. DeBeer, T. Weyhermüller, S. Sproules and K. Wieghardt, Inorg. Chem., 2012, 51, 3718.

13 M. Wang, J. England, T. Weyhermüller and K. Wieghardt, Inorg. Chem., 2014, DOI: 10.1021/ic4029854.

14 J. Hawecker, J.-M. Lehn and R. Ziessel, J. Chem. Soc., Chem. Commun., 1984, 328.

15 T. Yoshida, K. Tsutsumida, S. Teratani, K. Yasufuku and M. Kaneko, J. Chem. Soc., Chem. Commun., 1993, 631.

16 J. M. Smieja and C. P. Kubiak, Inorg. Chem., 2010, 49, 9283.

17 C. Caix, S. Chardon-Noblat and A. Deronzier, J. Electroanal. Chem., 1997, 434, 163.

18 C. M. Bolinger, N. Story, B. P. Sullivan and T. J. Meyer, Inorg. Chem., 1988, 27, 4582.

19 P. Paul, B. Tyagi, A. K. Bilakhiya, M. M. Bhadbhade, E. Suresh and G. Ramachandraiah, Inorg. Chem., 1998, 37, 5733.

20 H. Nagao, T. Mizukawa and K. Tanaka, Inorg. Chem., 1994, 33, 3415.

21 Z. Chen, C. Chen, D. R. Weinberg, P. Kang, J. J. Concepcion, D. P. Harrison, M. S. Brookhart and T. J. Meyer, Chem. Commun., 2011, 47, 12607.

22 M. Bourrez, F. Molton, S. Chardon-Noblat and A. Deronzier, Angew. Chem. Int. Ed., 2011, 50, 9903.

23 J. M. Smieja, M. D. Sampson, K. A. Grice, E. E. Benson, J. D. Froehlich and C. P. Kubiak, Inorg. Chem., 2013, 52, 2484.

24 A. R. Guadalupe, D. A. Usifer, K. T. Potts, H. C. Hurrell, A.-E. Mogstad and H. D. Abruna, J. Am. Chem. Soc., 1988, 110, 3462.

25 H. C. Hurrell, A. L. Mogstad, D. A. Usifer, K. T. Potts and H. D. Abruna, Inorg. Chem., 1989, 28, 1080.

26 C. Arana, S. Yan, M. Keshavarz-K, K. T. Potts and H. D. Abruna, Inorg. Chem., 1992, 31, 3680.

27 C. Arana, M. Keshavarz, K. T. Potts and H. D. Abruna, Inorg. Chim. Acta, 1994, 225, 285.

28 J. A. Ramos Sende, C. R. Arana, L. Hernandez, K. T. Potts, M. Keshevarez-K and H. D. Abruna, Inorg. Chem., 1995, 34, 3339.

29 A. Paul, D. Connolly, M. Schulz, M. T. Pryce and J. G. Vos, Inorg. Chem., 2012, 51, 1977.

30 P. Fuchs, U. Hess, H. H. Holst and H. Lund, Acta Chemica Scandinavica B, 1981, 35, 185.

31 C. Costentin, S. Drouet, M. Robert and J.-M. Savéant, J. Am. Chem. Soc., 2012, 134, 11235.

32 C. Costentin, M. Robert and J.-M. Saveant, Chem. Soc. Rev., 2013, 42, 2423.

33 S. Creager, in Handbook of Electrochemistry, ed. C. G. Zoski, Elsevier, Amsterdam, $1^{\text {st }}$ edn, 2007, ch. 3, pp. 101.
34 J.-M. Lehn and R. Ziessel, Proc. Nati. Acad. Sci. USA, 1982, 79, 701.

35 Z. Chen, P. Kang, M.-T. Zhang and T. J. Meyer, Chem. Commun., 2014, 50, 335 .

36 J. Qiao, Y. Liu, F. Hong and J. Zhang, Chem. Soc. Rev., 2014, 43, 631.

37 J. R. Pugh, M. R. M. Bruce, B. P. Sullivan and T. J. Meyer, Inorg. Chem., 1991, 30, 86.

38 C. Amatore and J.-M. Saveant, J. Am. Chem. Soc., 1981, 103, 5021.

39 G. D. Jones, J. L. Martin, C. McFarland, O. R. Allen, R. E. Hall, A. D. Haley, R. J. Brandon, T. Konovalova, P. J. Desrochers, P. Pulay and D. A. Vicic, J. Am. Chem. Soc., 2006, 128, 13175.

40 C. Hamacher, N. Hurkes, A. Kaiser, A. Klein and A. Schüren, Inorg. Chem., 2009, 48, 9947.

41 J. L. Dempsey, J. R. Winkler and H. B. Gray, J. Am. Chem. Soc., 2010, 132, 16774.

42 J. L. Dempsey, J. R. Winkler and H. B. Gray, J. Am. Chem. Soc., 2009, 132, 1060

43 J. L. Dempsey, B. S. Brunschwig, J. R. Winkler and H. B. Gray, Acc.Chem. Res., 2009, 42, 1995.

44 T. Lazarides, T. McCormick, P. Du, G. Luo, B. Lindley and R. Eisenberg, J. Am. Chem. Soc., 2009, 131, 9192.

45 M. M. Roubelakis, D. K. Bediako, D. K. Dogutan and D. G. Nocera, Energy Environ. Sci., 2012, 5, 7737.

46 V. Artero, M. Chavarot-Kerlidou and M. Fontecave, Angew. Chem. Int. Ed., 2011, 50, 7238.

47 R. Ziessel, J. Hawecker and J.-M. Lehn, Helvetica Chimica Acta, 1986, 69, 1065.

48 C. V. Krishnan, N. Sutin, J. Am. Chem. Soc., 1981, 103, 2141.

49 C. Creutz, H. A. Schwarz, N. Sutin, J. Am. Chem. Soc., 1984, 106, 3036.

50 Z. Han, L. Shen, W. W. Brennessel, P. L. Holland and R. Eisenberg, J. Am. Chem. Soc., 2013, 135, 14659.

51 J. Yang, S. E. Smith, T. Liu, W. G. Dougherty, W. A. Hoffert, W. S. Kassel, M. Rakowski Dubois, D. L. Bubois and M. Bullock, J. Am. Chem. Soc., 2013, 135, 9700.

52 A. D. Wilson, R. H. Newell, M. J. McNevin, J. T. Muckerman, M. Rakowski Dubois and D. L Dubois, J. Am. Chem. Soc., 2006, 128, 358.

53 J. Y. Yang, R. Morris Bullock, W. J. Shaw, B. Twamley, K. Fraze, M. Rakowski Dubois and D. L. Dubois, J. Am. Chem. Soc., 2009, 131, 5935.

54 S. Daniele, P. Ugo, G. Bontempelli and M. Fiorani, J. Electroanal. Chem., 1987, 219, 259.

55 B. P. Sullivan, C. M. Bolinger, D. Conrad, W. J. Vining and T. J. Meyer, J. Chem. Soc., Chem. Commun., 1985, 1414.

56 D. Chen, P.-L. Fabre and O. Reynes, Electrochimica Acta, 2011, 56, 8603.

57 G. Fachinetti, T. Funaioli and P. F. Zanazzi, J. Chem. Soc., Chem. Commun., 1988, 1100.

58 E. Fujita, D. J. Szalda, C. Creutz and N. Sutin, J. Am. Chem. Soc., 1988, 110, 4870.

59 J. Nath, D. Kalita and J. B. Baruah, Polyhedron, 2011, 30, 2558.

60 T. Duangthongyou, C. Phakawatchai and S. Siripaisarnpipat, Journal of Molecular Structure, 2011, 987, 101.

61 K. Dimitrou, K. Folting, W. E. Streib and G. Christou, J. Am. Chem. Soc., 1993, 115, 6432.

62 S. Bhaduri, N. Y. Sapre and A. Basu, J. Chem. Soc., Chem. Commun., 1986, 197.

63 S. Romain, C. Baffert, C. Duboc, J.-C. Leprêtre, A. Deronzier and M.N. Collomb, Inorg. Chem., 2009, 48, 3125.

64 U. S. Schubert, C. Eschbaumer, P. Andres, H. Hofmeier, C. H. Weidl, E. Herdtweck, E. Dulkeith, A. Morteani, N. E. Hecker and J. Feldmann, Synthetic Metals, 2001, 121, 1249.

65 S. B. Jones, C. M. Terry, T. E. Lister and D. C. Johnson, Anal. Chem., 1999, 71, 4030. 